\title{
Pengelolaan Laboratorium IPA untuk Meningkatkan
Mutu Pembelajaran Peserta Didik (Studi Kasus di MTS
Negeri 1 Garut dan MTS Cilawu Nurul Amin)
}

Ferra Nurdianti Rostiyana ${ }^{1}$, Achmad Sanusi ${ }^{2}$, Yosal Iriantara ${ }^{3}$

1,2,3Sekolah Pascasarjana, Universitas Islam Nusantara Bandung, Indonesia

E-mail:ferra.rostiyana@gmail.com,achmad_sanusi11@gmail.com,yosal.irinatara@gmail.com

\begin{tabular}{l}
\hline Article Info \\
\hline Article History \\
Received: $2021-12-27$ \\
Revised: $2022-01-22$ \\
Published: $2022-02-02$
\end{tabular}

Keywords:

Management;

Science Laboratory;
Quality of Learning.

\begin{abstract}
The general aim of this research is to obtain a clear picture of laboratory management at MTs Negeri 1 Garut and MTs Cilawu Nurul Amin. The specific purpose of this research is to describe about; (1) Planning, (2) Organizing, (3) Implementation, (4) Supervision and (5) Supporting and inhibiting factors in the management of the science laboratory to improve the quality of learning for students at MTs Negeri 1 and MTs Nurul Amin, Garut Regency. This study uses a qualitative approach with naturalistic methods, the subject in this study is the principal, waka in the field of infrastructure. Laboratory coordinator and science subject teacher. Data collection techniques were carried out by means of observation, interviews and documentation studies. The conclusion shows that the management of the science laboratory at MTs Negeri 1 Garut and MTs Cilawu is adequate and well implemented. All stages of management which include planning, organizing, implementing and monitoring have been carried out. This shows that the head of the madrasah, representatives of infrastructure, science laboratory coordinators and science teachers have carried out their duties as managers of science laboratories optimally, although they are still facing various obstacles such as the lack of funding for science laboratories.
\end{abstract}

\begin{tabular}{l} 
Artikel Info \\
\hline Sejarah Artikel \\
Diterima: $2021-12-27$ \\
Direvisi: 2022-01-22 \\
Dipublikasi: 2022-02-02
\end{tabular}

Kata kunci:

Pengelolaan;

Laboratorium IPA;

Mutu Pembelajaran. \begin{abstract}
Abstrak
Tujuan secara umum penelitian ini untuk memperoleh gambaran yang jelas mengenai pengelolaan laboratorium di MTs Negeri 1 Garut dan MTs Cilawu Nurul Amin. Tujuan secara khusus penelitian ini ingin mendeskripsikan tentang; (1) Perencanaan, (2) Pengorganisasian, (3) Pelaksanaan, (4) Pengawasan dan (5) Faktor-faktor pendukung serta penghambat dalam pengelolaan laboratorium IPA untuk meningkatkan mutu pembelajaran peserta didik di MTs Negeri 1 dan MTs Nurul Amin Kabupaten Garut. Penelitian ini menggunakan pendekatan kualitatif dengan metode naturalistik, subjek dalam penelitian ini adalah kepala sekolah, waka bidang sarana prasarana. Koordinator laboratorium dan Guru mata pelajaran IPA. Teknik pengumpulan data dilakukan dengan cara obsevasi, wawancara dan studi dokumentasi. Kesimpulan menunjukan bahwa Pengelolaan laboratorium IPA di MTs Negeri 1 Garut dan MTs Cilawu sudah memadai dan dilaksanakan dengan baik. Semua tahap pengelolaan yang mencakup perencanaan, pengorganisasian, pelaksanaan dan pengawasan telah dilaksanakan. Ini menunjukan bahwa Kepala madrasah, wakil sarana prasarana, koordinator laboratorium IPA dan Guru IPA telah melakukan tugasnya sebagai pengelola laboratorium IPA dengan optimal, walaupun masih menghadapi berbagai kendala seperti minimnya pendanaan terhadap laboratorium IPA.
\end{abstract}

\section{PENDAHULUAN}

Sekolah adalah sebuah institusi pendidikan yang dalam pencapaian tujuannya sangat didukung oleh berbagai komponen, salah satunya adalah Laboratorium IPA, untuk meningkatkan mutu pembelajaran peserta didik dan mencapai tujuan belajar seperti tercantum dalam UU No. 20 Tahun 2003 tentang Sistem Pendidikan Nasional pada pasal 3, yang menyatakan "Pendidikan nasional berfungsi mengembangkan kemampuan dan membentuk karakter serta peradaban bangsa yang bermartabat dalam rangka mencerdaskan kehidupan bangsa" maka Sekolah harus mempunyai standar sarana dan prasarana yang menunjang mutu pembelajaran peserta didik, seperti yang tercantum dalam Permendiknas No. 24 Tahun 2007 tentang Standar Sarana dan Prasarana Pasal 1 ayat 1 yang meliputi: Standar sarana dan prasarana untuk sekolah dasar/ madrasah ibtidaiyah (SD/MI), sekolah menengah pertama/ madrasah tsanawiyah (SMP/MTs), dan sekolah menengah atas/ madrasah aliyah (SMA/MA) mencakup kriteria minimum sarana dan kriteria minimum prasarana. Lebih dari itu Laboratorium IPA adalah komponen yang sangat mendasar dalam terlaksananya suatu proses pendidikan untuk mencapai hasil pembelajaran yang lebih baik. Laboratorium adalah tempat pembelajaran sains IPA dengan cara mencari pengetahuan tentang 
alam secara sistematis melalui proses penemuan (inquiry) yang menekankan pemberian pengalaman langsung dalam penggunaan dan pengembangan keterampilan proses dan sikap ilmiah peserta didik, yang bermuara pada pembelajaran Work-Based eksperimen (belajar sambil bekerja). Keberadaan Laboratorium IPA juga perlu didukung oleh sebuah program yang baik agar dapat mencapai tujuan yang direncanakan dan mengacu kepada Visi dan Misi Sekolah.

Jika dilihat kondisi yang terjadi di MTs Kabupaten Garut, pengelolaan di laboratorium IPA dirasakan masih kurang optimal dalam unit penyediaan air dan pengelolaan air, unit penyediaan steam, unit pengelolaan limba. Kepala Sekolah dan kepala laboratorium mempunyai tugas menyusun perencana dan program seperti program pengadaan kebutuhan alat-alat laboratorium, mengkoordinir kegiatan laboratorium, membuat jadwal dan pengaturan, mengembangkan struktur organisasi, memberikan pendelegasian tugas secara jelas kepada bawahannya, mengontrol pelayanan, administrasi, pemeriksaan, bahan, alat serta seluruh operasional pelayanan. Seorang kepala laboratorium dan laboran harus diberi pelatihan khusus agar keterampilan dalam mengelola laboratorium lebih profesional. Dengan adanya pengelolaan laboratorium yang profesional maka dapat membantu guru dan siswa dalam proses belajar demi terciptanya pembelajaran IPA yang maksimal. Laboratorium dari sarana praktikum IPA merupakan aset sekolah yang sangat berharga. Pengelola laboratorium harus bisa keterampilan proses dalam pengelolaan laboratorium IPA sesuai standar kurikulum yang berlaku. Berdasarkan Permendiknas No. 26 tahun 2008 tentang Standar Tenaga Pengelolaan Laboratorium Sekolah/ Madrasah, pengelolaan laboratorium IPA meliputi mengkoordinasikan kegiatan praktikum dengan guru, menyusun jadwal kegiatan laboratorium, memantau pelaksanaan dan kegiatan laboratorium dan mengevaluasi kegiatan laboratorium. Oleh karena itu pengelola laboratorium IPA di sekolah disesuaikan dengan peraturan menteri tersebut, dengan demikian laboratorium akan menjadi sarana penunjang dalam pelaksanaan proses belajar mengajar, guna meningkatkan kualitas hasil belajar siswa. Sehubungan dengan itu berarti pengelola dalam mengelola laboratorium secara spesifik dituntut untuk memiliki profesionalisme dalam melaksanakan pekerjaannya. Pengelola harus menguasai pengetahuan pengelolaan laboratorium IPA. Jika kemampuan tersebut rata-rata dimiliki oleh para pengelola laboratorium maka akan mampu memberikan kontribusi dalam meningkatkan pencapaian tujuan pembelajaran IPA.

Pendidikan Ilmu Pengetahuan Alam (IPA) yang baik haruslah dapat menghasilkan perubahan tingkah laku yang penting, yaitu minat, pengertian, sikap, kemampuan berfikir dan keterampilan, untuk mengembangkan dan mendorong perubahan tingkah laku yang penting tersebut diperlukan adanya pendekatan yang mendorong dan mengembangkannya, yaitu dengan melalui pendekatan inquiry dan pendekatan proses. Salah satu sarana yang dianggap ampuh untuk melaksanakan pendekatanpendekatan tersebut ialah laboratorium sehingga kegiatan belajar mengajar IPA dapat berjalan lancar dan efektif, dengan adanya laboratorium, siswa dapat melakukan kegiatan untuk menemukan jawaban terhadap masalah yang berhubungan dengan IPA baik secara berkelompok maupun perorangan. Proses belajar dengan menggunakan alat peraga/ praktikum membuat siswa memiliki tanggapan yang jelas dari rangsangan yang diberikan sehingga dapat meninggalkan kesan pengamatan yang sempurna pada diri setiap siswa. Siswa tidak hanya mendengarkan ceramah dari guru, tetapi juga dapat melihat, melakukan sendiri, atau berkelompok melalui percobaan laboratorium. Mereka juga akan tahu dan mengerti serta memahami. Pengertian serta pemahaman yang diperoleh melalui pengamatan dan percobaan yang dilakukan sendiri akan dapat bertahan lama dan sukar dilupakan. Dengan melakukan praktikum dapat menciptakan aktivitas dan daya kreativitas yang lebih tinggi bagi setiap siswa.

Risa (1987:8) menyatakan bahwa laboratorium mampu berperan untuk memotivasi dan mengembangkan minat, pengertian, kemampuan berfikir, sikap dan ketrampilan para peserta didik. Menurut Emha (2002:4) apabila proses belajar mengajar dilakukan tanpa menggunakan alat peraga/ praktikum, hal ini akan meninggalkan kesan verbalis, para peserta didik akan tahu tetapi tidak mengerti dan pengetahuan ini tidak menimbulkan kesan dan rangsangan bagi peserta didik dan dengan sendirinya akan mudah hilang dari ingatan, dilihat adanya gambaran tentang kendala dan kelemahan yang dihadapi dalam masalah manajemen laboratorium. Terlihat tugas dari kepala laboratorium belum memadai. Belum terlihat adanya pe-rencanaan yang matang dalam kegiatan laboratorium. Seorang perencana harus mampu untuk menggambarkan (visualisasi) pola kegia-tan 
yang diusulkan itu secara jelas dan gamblang (Terry, 2009:47). Perlu harmonisasi programprogram dan kebijaksanaan-kebijaksanaan dengan mengecek konsistensi dan mensinkronkan waktu. Pengawasan didalam administrasi, pemeriksaan bahan dan alat juga dirasakan kurang.

Demikian pula dengan laboran dalam pekerjaannya tidak fokus di laboratorium. Laboran dalam kesehariannya terlihat bekerja selalu diiringi dengan pekerjaan lain seperti membersihkan ruangan-ruangan lain, mem-bersihkan halaman sekolah, menyiram tanaman bahkan sampai membuang sampah pada tempat-nya. Sepertinya laboran juga kurang memahami tentang fasilitas yang ada di laboratorium. Laboran hanya mengetahui beberapa saja tentang nama-nama alat dan bahan praktikum. Tata letak alat dan bahan juga tidak memadai. Terlihat laboratorium yang tidak terawat, carta, torso dan peralatan praktikum lainnya yang sangat berdebu, peralatan yang masih utuh terbungkus rapi karena belum dipakai, sedangkan yang sudah terpakai terlihat kotor tanpa dibersihkan. Ada alat-alat laboratorium dan bahan yang sudah rusak yang belum diperbaiki dan diadakan kembali. Padahal pemeliharaan dan perawatan alat-alat merupakan bagian dari kegiatan pengelolaan laboratorium yang paling penting dilakukan untuk menjaga agar alat-alat laboratorium dapat digunakan sesuai dengan batas usia pakainya. Pengelolaan Laboratorium IPA di MTs yang ada di Garut pada saat ini masih dilakukan secara bersama-sama antara Guruguru bidang studi yang menggunakan Laboratorium tersebut. Tanggung jawab pengadaan dan pemeliharaan juga diserahkan kepada masingmasing guru bidang studi, selain itu pengadaan alat-alat dan bahan juga diserahkan masih belum efektif.

Sekolah yang juga memiliki masalah serupa dalam pengelolaan laboratorium IPA yang meliputi perencanaan, pengorganisasian, pelaksanaan, pengawasan dan evaluasi adalah MTs Negeri 1 Garut dan MTs Cilawu Nurul Amin. Sekolah tersebut merupakan salah satu sekolah negeri dan swasta yang terletak di Kabupaten Garut, berdasarkan data awal, menunjukkan bahwa standar sarana dan prasarana di sekolah tersebut sudah sesuai dengan Permendiknas No. 24 Tahun 2007 tentang Standar Sarana dan Prasarana. Terlihat bahwa sekolah tersebut sudah memiliki ruang laboratorium yang mengkhusus, tidak lagi ruang kelas yang digunakan untuk ruang laboratorium, namun penerapan pengelolaan laboratorium IPA di sekolah belum sesuai dengan Permendiknas RI No. 26 Tahun 2008 tentang Standar Tenaga Laboratorium Sekolah/Madrasah. Beberapa masalah yang ditemukan pada laboratorium sekolah ini yaitu sekolah belum memiliki tenaga laboran yang dapat membantu mempersiapkan kegiatan praktikum maupun pengelolaan laboratorium, melainkan guru IPA yang merangkap menjadi seorang laboran. Perencanaan dalam pengelolaan laboratorium belum dilakukan dengan baik misalnya dalam menyusun program kerja laboratorium, pelaksanaan kegiatan laboratorium sekolah juga belum berjalan dengan baik, contohnya pada saat penyediaan alat dan bahan laboratorium. Pengorganisasian dalam mengelola laboratorium belum dibuat dengan jelas, contohnya jika ada pergantian pengurus struktur organisasi tidak segera diperbaiki, kemudian untuk tenaga laboran sendiri guru IPA yang merangkap sebagai seorang laboran, tidak ada tenaga laboran secara khusus, pengawasan dan evaluasi sangat penting untuk mengetahui kegiatan-kegiatan praktikum sudah berjalan dengan baik atau belum, kemudian apakah didalam pelaksanaannya itu ada kendala yang bisa menghambat kegiatan laboratorium.

\section{METODE PENELITIAN}

Penelitian ini dilakukan dengan menggunakan metode naturalistik kualitatif yaitu pendekatan yang diarahkan pada latar dan individu secara holistic (utuh). Penelitian ini dimaksudkan untuk mengungkap, menggali dan menemukan informasi yang mendalam dan komprehensif tentang implementasi manajeman kepala laboratorium IPA. Metode Naturalistik kualitatif dipilih karena data tentang gejala-gejala yang akan diperoleh dilapangan lebih banyak menyangkut perbuatan dan kata-kata dari subjek penelitian, bersifat alami, apa adanya, tidak ada unsur rekayasa dari pihak manapun dan tidak terpengaruh oleh unsur-unsur eksternal. Penelitian dilakukan dalam situasi yang alami dan natural, setting tanpa diadakan treatment atau control terhadap subjek penelitian dan sesuai dengan keadaan yang sebenarnya. Pendekatan dalam penelitian ini menggunakan pendekatan kualitatif. Penelitian kualitatif yaitu penelitian penelitian yang tidak menggunakan perhitungan (Moleong, 2002:2). Teknik pengumpulan data yang digunakan dalam penelitian ini adalah Observasi, studi dokumentasi, dan wawancara. Ketiga teknik ini dipergunakan untuk memperoleh data dan informasi yang saling berhubungan dan saling melengkapi tentang pengelolaan laborato- 
rium IPA. Sedangkan instrumen yang digunakan adalah peneliti artinya peneliti secara langsung berinteraksi dengan lingkungan masalah yang diteliti. Sesuai dengan judul penelitian maka lokasi untuk penelitian adalah Sekolah Madrasah Tsanawiah Negeri 1 Garut dan Sekolah Madrasah Tsanawiah Nurul Amin Kecamatan Cilawu Kabupaten Garut.

\section{HASIL DAN PEMBAHASAN}

\section{Hasil Penelitian}

1. Hasil Penelitian di MTS Negeri 1 Garut

a) Perencanaan Laboratorium IPA di MTs Negri 1 Garut

Berdasarakan hasil wawancara, observasi dan dokumentasi pada penelitian ini memberikan gambaran bahwa rencana program kerja laboratorium IPA di MTs Negeri 1 Garut sampai saat ini sudah tersusun dengan baik. Kedua, kurangnya koordinasi dan kerja sama antara Kepala madrasah dan wakil Kepala madrasah bidang sarana prasarana dengan Koordinator laboratorium IPA dan atara Koordinator laboratorium IPA dengan Guru-guru matapelajaran IPA dalam menyusun program kerja jangka pendek, menengah dan panjang. Kondisi ini menghambat upaya peningkatan kualitas laboratorium IPA, karena tanpa adanya perencanaan yang baik dan matang, suatu program tidak akan segera ditindak lanjuti dengan menyusun program jangka pendek, menengah dan panjang dengan pembagian tugas yang jelas.

b) Pengorganisasian Laboratorium IPA di MTs Negri 1 Garut

Hasil penelitian tersebut memberikan gambaran bahwa pengorganisasian laboratorium IPA sudah berjalan dengan baik, struktur organisasi sudah terpasang diruangan laboratorium, Kepala madrasah sudah menentukan personil setiap tahun ajaran baru dengan melibatkan semua pihak terkait. Sistem pengadministrasiannya sudah berjalan dengan baik, koordinator laboratorium IPA memiliki buku laporan mengenai inventarisasi alat-alat kegaiatan laboratorium IPA.

c) Pelaksanaan Program Kerja Laboratorium IPA di MTs Negeri 1 Garut

Hasil penelitian tersebut memberikan gambaran bahwa secara umum laboratorium IPA di MTs Negeri 1 Garut sudah memenuhi stndar laboratorium minimal tingkat SMP/MTs yang direkomendasikan oleh Kementerian Agama, proses pengadaan modul praktikum IPA dilaboratorium belum berjalan dengan baik dikarenakan masingmasing guru IPA memiliki cara tersendiri dalam menyampaikan materi pembelajaran, sebagian guru menciptakan materi pembelajaran sendri dan sebagian lagi mengunakan buku pelajaran dari penerbit tertentu. Namun materi-materi tersebut hanya digunakan oleh Guru-guru IPA pada pembelajaran tertentu.

d) Pengawasan Terhadap Pelaksanaan Program Kerja Laboratorium IPA di MTs Negeri 1 Garut

Hasil penelitan tersebut memberikan gambaran bahwa untuk dapat melakukan pembinaan, maka Kepala madrasah hars secara rutin melaksanakan kegiatan supervisi kepada Guru-guru, walaupun dengan cara memberikan penugasan kepada Guru-guru senior atau para pembantu Kepala madrasah, Kepala madrasah telah melakukan pembinaan kepada Guru-guru yang tidak melaksanakan tugasnya dengan baik atas laporan dari Guru-guru senior yang telah melakukan supervisi dan ditemukan ada kekurangan dalam pembelajran atau dalam melaksanakan tugasnya. Kepala madrasah memberi-kan pembinaan secara khusus apabila diperlukan kepada guru yang tujuannya untuk meningkatkan guru agar melaksanakan tugasnya dengan lebih baik lagi.

e) Faktor-faktor Pendukung dan Penghambat dalam Pengelolaan Laboratorium IPA di MTs Negeri 1 Garut

Kegiatan operasional dalam pengelolaan laboratorium tidak terlepas dari masalah biaya, sumber dana yang digunakan untuk pengelolaan laboratorium IPA diperoleh dari dana BOS dan komite sekolah, belum adanya tugas khusus pengelola laboratorium IPA juga menjadi salah satu penghambat dalam pengelaaan laboratorium karena sampai saat ini masih banyak ditemukan guru IPA yang memiliki pengetahuan dan pengalaman yang minim tentang labora- 
torium sehingga sangat diperlukan sekali pelatihan atau penataran khusus mengenai pengelolaan laboratorium IPA. Selain itu laboratorium IPA di MTs Negeri 1 Garut masih menerapkan tata letak ruangan yang tidak memenugi standar minumin laboratorium, bentuk ruangan laboratorium yang sama dengan ruangan kelas akan memberikan beberapa dampak negatif terhadap pencapaian tujuan pembelajaran IPA di laboratorium. Dampak tersebut antara lain adanya sekat anatara para Peserta didik selama praktikum akan menyulitkan Peserta didik untuk saling berinteraksi, minimnya akses guru ke Peserta didik secara langsung, baik untuk memonitor maupun membantu selama praktikum terutama untuk Peserta didik yang duduk paling belakang serta mengurangi fleksibilitas cara mengajar guru.

2. Hasil Penelitian di MTs Nurul Amin Cilawu Garut

1) Perencanaan Laboratorium IPA di MTs Cilawu

Berdasarkan hasil penelitian yang telah dilakukan memberikan gambaran bahwa rencana program kerja laboratorium IPA MTs Cilawu sampai saat ini sudah tersusun dengan cukup baik, rencana sudah disusun secara tertulis, perencanaan itu pun sudah mengarah pada tujuan yang hendak dicapai, sudah ada koordinasi dan kerja-sama antara kepala sekolah dan PKS bidang sarana dan prasarana dengan Koordinator laboratorium IPA dan anatar Koordinator laboratorium IPA dengan Guruguru Ipa dalam menyusun program kerja baik untuk jangka pendek, jangka menengah dan jangka panjang yang sudah ditindak lanjuti dengan penyusunan program yang baik.

2) Pengorganisasian Laboratorium IPA di MTs Cilawu

Berdasarkan hasil wawancara, observasi dan dokumentasi penelitian tersebut memberikan gambaran bahwa Pengorganisasian labratorium IPA di MTs Cilawu sudah berjalan dengan baik seperti, sturktur organisasi sudah ditempelkan di ruangan laboratorium dan Kepala madrasah sudah menunjuk Koordinator laboratorium IPA setiap tahun pelajaran baru dengan melibatkan semua pihak yang terkait, sistem administrasinya juga sudah berjalan dengan baik.

3) Pelaksanaan Program Kerja Laboratorium IPA di MTs Cilawu

Berdasarkan hasil wawancara, observasi dan dokumentasi penelitian tersebut memberikan gambaran bahwa secara umum laboratorium IPA di MTs Cilawu sudah memenuhi standar laboratorium minimal untuk tingkat SMP/MTs yang direkomendasaikan oleh Kementrian Agama, hanya saja di dalam ruangan laboratorium ada beberapa peralatan yang rusak seperti tabung erlenmeyer, proses pengadaan modul di laboratorium IPA sudah berjalan dengan baik karena guru mengajukan pengadaan buku lewat Koordinator laboratorium IPA, selanjutnya Koordinator laboratorium IPA minta persetujuan Kepala madrasah untuk pengadaan buku tersebut, disamping itu masing-masing guru memiliki cara tersendiri dalam menyampaikan materi pembelajaran.

4) Pengawasan Terhadap Pelaksanaan Program Kerja Laboratorium IPA di MTs Cilawu

Berdasarkan hasil wawancara, observasi dan dokumentasi penelitian tersebut memberikan gambaran bahwa: Pertama, Kepala madrasah melakasanakan supervisi tigas jenis yaitu, supervisi administras program kerja setiap awal tahun pelajaran, supervisi penggunaan setap akhir bulan, dan supervisi fisik setiap 3 bulan sekali. Kedua, Kepala madrasah memberikan sanksi terhadap guru yang tidak melaksanakan tugasnya dengan baik, walaupun Kepala madrasah hanya memberikan himbauan dan teguran yang tujuannya untuk meningkatkan kinerja dan kualitas guru agar lebih baik lagi sebagai tindak lanju dari kegiatan supervisi.

5) Faktor-faktor Pendukung dan Penghambat dalam Pengelolaan Laboratorium IPA di MTs Cilawu

Kegiatan operasional dalam pengelolaan laboratorium tidak terlepas dari masalah biaya, dari hasil wawancara peneliti dengan Kepala madrasah MTs 
Cilawu terungkap bahwa alokasi dana untuk kegiatan laboratorium IPA memang dianggarkan dan dianggap mencukupi. Setiap anggaran harus dialokasikan untuk pengelolaan laboratorium IPA dan mendapatkan persetujuan ketua komite sekolah terlebih dahulu, diungkapkan bedaharawan sekolah bahwa dana untuk kegiatan laboratorium IPA memang ada, namun jumlahnya terbatas, walaupun demikian, menurut Koordinator laboratorium IPA dalam pelaksanaannya ternyata kegiatan di laboratorium dapat berjalan lancar. Selain itu laboratorium IPA di MTs Cilawu masih menerapkan tata letak ruangan yang tidak memenugi standar minumin laboratorium, bentuk ruangan laboratorium yang sama dengan ruangan kelas akan memberikan beberapa dampak negatif terhadap pencapaian tujuan pembelajaran IPA di laboratorium.

\section{Pembahasan}

\section{Perencanaan Laboratorium IPA}

Perencanaan adalah suatu proses untuk menentukan rencana, dalam manajemen, perencanaan dan rencana merupakan bagian yang sangat penting, karena tanpa perencanaan dan rencana berarti tidak ada tujuan yang ingin dicapai tanpa perencanaan dan rencana tidak ada pedoman pelaksanaan sehingga banyak pemborosan, rencana adalah dasar pengendalian, karena tanpa ada rencana pengendalian tidak akan dilakunan tanpa perencanaan dan renana berarti tidak ada keptusan dan proses manajeman pun tidak ada (Hasibuan, 205;91). Perencanaan laboratorium IPA di MTs Negeri 1 Garut dan MTs Cilawu Nurul Amin sudah baik, Koordinator laboratorium IPA selalu membuat rencana jangka panajang, program semester dan program tahunann secara rutin, sehingga pengguna laboratorium IPA bisa berjalan dengan baik sesuai dengan tujuan penggunaan laboratorium IPA, yaitu meningkatkan mutu pembelajaran.

\section{Pengorganisasian Laboratorium IPA}

Pengorganisasian laboratorium IPA meliputi pengaturan dan pemeliharaan peralatan dan sumber belajar, pengadaan sumber belajar yang lebih lengkap dan keselamatan kerja dilaboratorium (Depdikbud 1994:25). Mengorganisasikan labrato- rium IPA berarti menyusun kelompok orang atau petugas dan sumber daya yang lain unuk melaksanakan satu rencana atau program kerja guna mencapai tujuan yang telah ditetapkan. Struktur organisasi laboratorium IPA juga memegang peranaan penting karena struktur tersebut memuat pembagian tugas dan wewenang dalam mengelola laboratorium, struktur organisasi laboratorium IPA di MTs Negeri 1 Garut dan MTs Cilawu Nurul Amin sudah berjalan dengan baik, karena Kepala madrasah menunjuk Koordinator laboratorium IPA setiap awal tahun pelajaran. Koordinator laboratorium IPA bertugas mengatur jadwal penggunaan laboratorium IPA, sehingga kegiatan penggunaan laboratorium untuk pembelajaranpun berjalan dengan baik.

3. Pelaksanaan Program Kerja Laboratorium IPA

Pelaksanaan merupakan salah satu fungsi manajemen yang sangat penting, sebab tanpa pelaksanaan apa yang telah direncanakan dan diorganisasikan tidak akan pernah menjadi kenyataan. Terry (1977:371) mengungkapkan bahwa: "Actuanting is getting all members of the group to want to achieve and ti strike ti achieve the objectives of the members because the members want to achieve these objectives." Pendapat tersebut meberikan pengertian bahwa pelaksanaan adalah menggerakan semua anggota kelompok agar bisa bekerja sama untuk mencapai tujuan dan cita-cita yang telah ditetapkan bersama, pelaksanaan program kerja laboratorium, penataan dan pengadministrasian peralatan laboratorium, serta pelaporan keuangan laboratorium.

4. Pengawasan terhadap Pelaksanaan Program Kerja Laboratorium IPA

Supervisi adalah sebagai acuan penilaian dan pengawasan Kepala madrasah terhadap kinerja guru. Arikunto (2004:13) menyatakan bahwa tiga fungsi supervisi atau pengawasan yaitu sebagai kegiatan meningkatkan mutu pembelajaran, sebagai pemicu atau penggerak terjadinya perubahan pada unsur-unsur yang terkait denga pembelajaran dan sebagai kegiatan memimpin dan membimbing. Terungkap dalam penelitian di MTs Negeri 1 Garut, Kepala madrasah telah melakukan super- 
visi secara baik terhadap pengelolaan maupun pembelajaran di laboratorium IPA, maupun dengan cara mendelegasikan atau memberikan tugas tersebut kepada pembantu-pembantu Kepala madrasah atau Guru-guru senior untuk melakukan supervisi, untuk dapat melakukan pembinaan, maka Kepala madrasah harus secara rutin melakukan kegiatan supervisi kepada Guru-guru. Namun Kepala madrasah memberikan tugas kepada pembantu-pembantu Kepala madrasah dan Guru-guru senior untuk melakukan supervisi dan melaporkan hasilnya kepada Kepala madrasah. Kepala madrasah akan memberikan tindak lanjut dari hasil supervisi yang dilakukan oleh PKS dan guru-gur senior, kondisi yang berbeda ditemukan saat peneliti melakukan penelitian di MTs Cilawu. Kepala madrasah MTs Cilawu secara rutin melaksanakan sipervisi dengan menggunakan format yang ada, terdapat tiga jenis supervisi yang dilakukan oleh Kepala madrasah yaitu supervisi administrasi dilakukan setiap awal pelajaran, supervisi kegiatan dilakukan setiap akhir bulan dan supervisi fisik dilakukan setiap tiga bulan, sehingga laboratorium IPA di MTs Cilawu berjalan cukup baik.

5. Faktor-faktor Pendukung dan Penghambat dalam Pengelolaan Laboratorium IPA

Dukungan dana untuk kegiatan operasional untuk kegiatan laboratorium bahasa sangat penting, selama ini dana yang tersedia dirasakan cukup untuk menunjang proses belajar-mengajar di laboratorium, dana yang tersedia ini dirasakan masih kurang dan masih mengandalkan bantuan dari pemerintah. Kreativitas Guru-guru IPA dalam memanfaatkan peralatan yang ada di laboratorium IPA ketika sebuah alat ada yang rusak juga merupakan pendukung dalam pembelajaran di laboratorium IPA. Pembelajaran praktikum tetap dilaksanakan ketika Mikroskop rusak dengan cara memanfatkan gambar pembelajaran dan video pembelajaran IPA. Belum adanya tenaga khusus pengelola laboratorium atau laboran juga menjadi salah satu penghambat dalam pengelolaan laboratorium IPA, karena waktu dan kemampuan koordinator laboratorium sangat terbatas sehingga diperlukan pelatihan atau penataran khusus tentang pengelolaan laboratorium IPA.
Selain itu, laboratorim IPA di MTs Negeri 1 Garut dan MTs Cilawu Nurul Amin masih menerapkan tata letak ruangan yang tidak memenuhi standar minimal laboratorium. Bentuk ruangan laboratorium yang sama dengan ruangan kelas akan memberikan beberapa dampak negatif terhadap pencapaian tujauan pembelajaran IPA di laboratorium. Dampak tersebut antara lain dengan adanya sekat antara para siswa selama praktikum akan menyulitkan siswa untuk berinteraksi, minimnya akses guru ke siswa secara langsung, baik untuk memonitor maupun membantu dalam Praktikum serta mengurangi fleksibilitas cara mengajar guru.

\section{SIMPULAN DAN SARAN}

\section{A. Simpulan}

Berdasarkan penelitian yang telah dilakukan, maka dapat disimpulkan:

1. Perencanaan dalam pengelolaan laboratorium IPA sudah tersusun dengan baik, karena perencanaan telah dituangkan secara tertulis untuk pengadministrasian. Selain itu rencana tersebut telah menjabarkan tujuan yang akan dicapai serta langkah-langkah yang akan dilakukan pada waktu yang ditentukan.

2. Pengorganisasin dalam pengelolaan laboratorium IPA telah dilaksanakan dengan baik, karena setiap awal tahun pembelajaran selalu dilakukan pergantian pengurus laboratorium IPA mulai dari koordinator laboratorium IPA dan anggotanya. Pengorganisasian ini dilakukan untuk melakukan pembenahan terhadap laboratorium IPA dengan koordinator yang baru, agar terciptanya program kerja yang baru dan selaras dengan visi misi madrasah.

3. Pelaksanaan program kerja laboratorium IPA secara umum juga telah berjalan dengan baik, karena dalam sistem administrasi laboratorium yang sudah terarsipkan dan koordinator laboratorium sudah memiliki buku laporan mengenai inventarisasi alat-alat. Namun pengelolaan pada dana anggaran masih terpusat pada bendaharawan sekolah.

4. Pengawasan dari Kepala madrasah sudah baik, sebab dalam hal ini Kepala madrasah sudah melakukan supervisi berdasarkan format yang ada, tindak lanjutnya digunakan untuk evaluasi dan perbaikan pengelolaan laboratorium IPA. koordinasi antara Kepala madrasah dan koordinator labora- 
torium IPA dilakukan untuk mengevaluasi kekurangan yang dialami oleh laboratorium IPA. Faktor pendukung yang ditemui dalam pengelolaan laboratorium IPA adalah adanya bantuan pendanaan laboratorium dari pemerintah dan sumber daya Guru-guru IPA yang handal dan bisa menyikapi bila ada peralatan yang tidak bisa digunakan atau tidak tersedia. Dana yang tersedia dari sekolah untuk penyediaan atau penambahan alat dan bahan laboratorium IPA sudah mencukupi, walaupun keuangan masih terpusat pada bendaharawan sekolah, sedangkan faktor penghambatnya adalah sebagian alat memerlukan peremajaan kembali. Selain itu tenaga pengelola khusus laboratorium belum ada, kurangnya alokasi waktu yang tersedia dalam kurikulum untuk melaksanakan praktikum IPA, serta tata letak ruangan laboratorium IPA di MTs Negeri 1 Garut dan MTs Cilawu Nurul Amin terlihat sama dengan bentuk ruangan kelas, meja kursi peserta didik di susun dengan format baris dan kolom.

\section{B. Saran}

Berdasarkan temuan saat melaksanakan penelitian, kiranya peneliti perlu memberikan rekomendasi kepada pihak sekolah maupun Dinas Pendidikan dan kementrian Agama Kabupaten Garut demi meningkatkan kualitas pengelolaan laboratorium IPA pada khususnya dan sekolah pada umumnya:

1. Sekolah perlu meningkatkan sarana dan prasarana laboratorium IPA seperti pembangunan gedung laboratorium yang representatif dan berstandar menurut Dinas pendidikan dan Kementrian Agama.

2. Kepala Madrasah perlu mengalokasikan dana untuk laboratorium IPA, khususnya untuk pengadaan peralatan praktikum serta pemeliharaan dan perbaikan alat-alat yang mengalami kerusakan.

3. Dalam upaya peningkatan layana kegiatan pembelajaran yang dilaksanakan di laboratorium, kemampuan dan keterampi-lan Guru-guru IPA perlu ditingkatkan melalui pelatihan atau penataran khusus tentang pengelolaan laboratorium untuk meningkatan mutu pembelajaran. dengan memberikan kesempatan dan dukungan kepada Guru dan peserta didik untuk mengembangkan kreativitias, kompetensi dalam mengelola laboratorium maupun adanya kerjasama dengan pihak lain untuk memperkaya khasanah media pembelajaran IPA. Perlu adanya bimbingan dan pengawasan dari Dinas Pendidikan dan kementrian Agama dalam merancang, mengelola dan mengupayakan laboratorium berfungsi secara efektif dan dapat termanfaatkan dengan baik dalam meningkatkan mutu pembelajaran.

\section{DAFTAR RUJUKAN}

Ali, L.U., dkk. (2013). Pengelolaan Pembelajaran IPA Ditinjau Dari Hakikat Sains Pada SMP Di Kabupaten Lombok Timur. eJournal Program Pascasarjana Universitas Pendidikan Ganesha Program Studi IPA, Vol.3 (hlm. 1)

Arikunto, S. (1998) Prosedur Penelitian. Jakarta: Rineka Cipta.

Atmadja, S. W. 2013. Menuju Pengelolaan Laboratorium Yang Lebih Baik,Dinas Pendidikan Kabupaten Klaten: Diklat Pengelolaan Laboratorium: Unwidha.co.id/workshoplaboratoriu mpengelolaan_laboatorium_pdf.

Badan Standar Nasional Pendidikan (BSNP). 2006. Standar Sarana dan Prasarana Sekolah/Madrasah Pendidikan Umum. Jakarta: Badan Standar Nasional Pendidikan.

Depdiknas. (2005). Standar Nasional Pendidikan Peraturan Pemerintah Nomor 19 Tahun 2005. Bandung: Fokus Media.

Fathirma'ruf, n., Asmedy, A., Budiman, B., \& Imansyah, M. (2021). PENGEMBANGAN EMODUL BERBANTUAN APLIKASI TEAM VIEWER DAN WHATSAPP UNTUK EFEKTIVITAS PRAKTIKUM JARAK JAUH DIMASA PANDEMI COVID-19. Kwangsan: Jurnal Teknologi Pendidikan, 9(2), 204-219.

doi:https://doi.org/10.31800/itp.kw.v9n2. p204--219

Kemendikbud. (2013). Kurikulum 2013, Kompetensi Dasar Sekolah Menengah Pertama (SMP)/Madrasah Tsanawiyah (MTs). Jakarta: Kemendikbud.

Kemendikbud.go.id. (2016, 6 Desember). Peringkat dan Capaian PISA Indonesia Mengalami Peningkatan. Diakses pada 6 
Desember 2016, dari

https://www.kemendikbud.go.id/main/bl og/2016/12/peringkatdancapaian-pisaindonesia-mengalamipeningkatan.

Marlina Leni. 2016. Manajemen Laboratorium Kimia. Jurnal Manajer Pendidikan. Vol.4. No.4.

Milles,M. Dan Huberman, A. (2007). Analisis Data Kualitatif (terjemahan tjetjep). Jakarta: UI Press

Moleong,L. (2005). Metode Penelitian Kualitatif. Bandung: PT. Remaja Rosdakarya.

Nanang Fattah. (2008). Landasan Manajemen Pendidikan. Bandung:: PT Remaja Rosdakarya.

Ngalim Purwanto. (2008). Administrasi dan Supervisi Pendidikan. Bandung: Remaja Rosdakarya.

Nurhayati B. (2010). Manajemen Laboratorium IPA pada SMP Negeri Kabupaten Purwakarta. Bandung: Tesis Uninus.

Oktaviani, Vita. (2013). Pentingnya Pendayagunaan Laboratorium Dalam Pembelajaran Fisika, Bandung: Program Studi Pendidikan Fisika, MIPA. (Mipaalwaysinmyheart.

Blogspot.com2013_05_01_archive.ht ml).

Poerwodarminto, W.J.S. (1986). Kamus Umum Bahasa Indonesia. PN. Balai Pustaka: Jakarta.

Risa, Nawas. (1987).Pengelolaan Laboratorium Sekolah Dasar, Bandung: Roda Pengetahuan.
Senta P \& Amoes, N. (2014). Pengelolaan Laboratorium IPA Studi Di SMP Negeri 80 Jakarta Timur. eJournal.uki.ac.id ManajemenPendidik an. Vol.3. No. 2

Sitorus, M \& Ani, S. (2013). Pengelolaan dan Manajemen Laboratorium Kimia. Yogyakarta : Graha Ilmu Subamia,dkk. (2014). Analisis Kebutuhan Tata Kelola Tata Laksana 129 Laboratorium IPA SMP Di Kabupaten Buleleng. Jurnal Pendidikan Indonesia. Vol.3.No.2.446-459.

Sugiarto, Bowo. (2008). Optimalisasi Pengelolaan Laboratrium IPA SMP. (htttp:/bowobiologi.blogspot.com/2008/10 /optimalisasi-pengelolaanlaboratorium.html).

Sugiyono. (2005). Memahami Penelitian Kualitatif. Bandung: CV.Alfabeta.

Sugiyono. (2013). Metode Penelitian Kuantitatif, Kualitatif, dan R\&D. Alfabeta:Bandung

Supriadi,D. (2006). Satuan Biaya Pendidikan. Bandung: PT. Remaja Rodaskarya.

Terry,G.R. (1993). Prinsip-prinsip Manajemen (Terjemahan: J. Smith. DFM). Jakarta: Bumi Aksara.

Terry, George R. 2009. Guide to Management, Alih bahasa J. Smith. D.F.M, Jakarta: Bumi Aksara. 